\title{
Labeled as Containing Natural Rubber Latex
}

National Cancer Institute

\section{Source}

National Cancer Institute. Labeled as Containing Natural Rubber Latex. NCI Thesaurus.

Code C101673.

The device label indicates natural rubber latex as a component. 